Journal of Development and Communication Studies, Vol. 5. No. 2, July 2017 - June 2018

ISSN (Online \& Print): 2305-7432.

http://www.devcomsjournalmw.org.

\title{
Community Access and Participation in Community Radio Broadcast: Case of Radio Gaakii, Ghana
}

\author{
Amadu Mohammed Faisal and Amin Alhassan \\ Faculty of Agribusiness and Communication Sciences, University for Development Studies, Tamale, Ghana. \\ Email.mfaisal@,uds.edu.gh
}

\begin{abstract}
This paper draws on the theory of participatory development communication to understand the nature and philosophy of community participation in development processes. It explored the symbiotic relationship between Carpentier (2011) and Arnstein's (1969) theses on participation to propose four major indicators in evaluating the levels of community participation in Radio Gaakii's broadcast. The paper also investigates the frequency of community members' participation in the stations broadcast and ascertained the levels of satisfaction (or otherwise) of their participation in the radio broadcast. The study was based on cross sectional survey design. Multistage sampling was used in the sampling processes and 150 respondents across five listening communities were recruited for the purposes of data collection and analysis. The study found out that community participation in Radio Gaakii's broadcast is limited to the radio programme listening stage and community members mostly participate through the use of mobile phones during specific programme phone-in segments of the broadcast. The study recommends establishing Radio Gaakii Listening Clubs to facilitate community's participation in management, governance, programming and financing decisions to give true meaning to participation, create a sense of community ownership and ultimately, ensure sustainability of the Station.
\end{abstract}

Key Words: Radio Gaakii, community radio, access, community participation, rural development, participatory development

https://dx.doi.org/10.4314/jdcs.v5i2.6

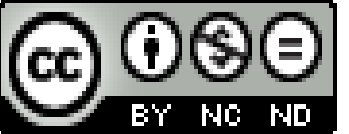

C) 2018. The Author. This work is licensed under the Creative Commons Attribution 4.0 International License (CC-By-NC-ND). Users may freely share and redistribute this work provided that the author and the Journal of Development and Communication Studies are fully acknowledged. Users may not tweak or remix and offer this work for sale. The full license may be accessed at https://creativecommons.org/licenses/by-nc-nd/4.0/

\section{Introduction}

Community access and participation are considered cardinal and significant components to the successes of development interventions. The lack of beneficiary community's participation in the conception, design, implementation as well as monitoring and evaluation, is often blamed for the failure of many development interventions (Leeuwis, 2004; Taylor, 1994; Cherdpong \& Flor, 2014).

The World Bank defined participation as "a process, through which stakeholders influence and share control over development initiatives and the decisions and resources which 
affect them" (World Bank, 1996). UNESCO's conception of participation gives a sense of equity and sustainability. This is to say that community members are in a well-informed position to influence decisions that have an impact on their lives and to also exercise control and ownership in development interventions so as to ensure project sustainability.

Participatory communication is defined as "that type of communication in which all the interlocutors are free and have equal access to the means to express their viewpoints, feelings and experiences" (Bordenave, 1994: 43). This reinforces the view that ordinary people have long years of experience which, if utilized, can bring about meaningful development to them (Freire, 1983). Therefore, providing opportunities for ordinary people to participate in decision-making enables them to express their knowledge about how they view the world and interpret development. "Rather than view themselves as somehow deficient or lacking in their ability to effect social change, communities could, through participatory methods, reassert and reclaim their capacity to transform their daily lives" (Howley, 2010: 184).

The distinguished pioneering scholarship of Professor Nora Cruz Quebral gave birth to the concept of development communication in 1971. Therefore, the concept of participatory development communication is closely associated with the College of Development Communication University of the Philippines Los Banos. As a field of practice, the pioneering scholarships of Quebrals' students including Celeste Cadiz, Felix Librero, Antonio Moran, Alexander Flor, Pedro Bueno, Rex Navaro, and other researchers such as Celia R. Taylor, Guy Bessette, among others heightened discussions of PDC as a valid and necessary approach to development interventions. Participatory communication encourages the critical engagement of development intervention beneficiaries in their own development processes. PDC therefore advocates for the devolution of knowledge, authority and control of development initiatives hitherto considered the preserve of interventionist, to truly reflect the aspirations, desires, needs and thinking of beneficiaries (Cherdpong \& Flor, 2014; Bordenave, 1994). Klees et al. (1986) asserts, "for advocates of grassroots development, participation has become the benchmark for measuring the effectiveness of grassroots processes" (cited in Tamminga, 1997: 94).

Participatory media projects are seen to "encourage individuals and groups to recognize their capacity to intervene in and redefine power relations within (and sometimes beyond) the local community" (Rodriguez, 2001 cited in Howley, 2010: 19). Participatory development projects such as Community Radio (CR) employ a participatory approach to decision making processes and enable the voiceless to define their own development paths through the identification and implementation of projects that are initiated by them (Mhagama, 2015). Rennie (2006: 134) sees participatory communication projects as "often small-scale, seeing specific bottom-up solutions as being more effective than general macro policies". Tapping into local knowledge is viewed as a necessary course of action if a development project is to be successful. It is what makes participatory communication projects truly unique (Howley, 2010).

Participation "comes in a variety of forms" (Zakus \& Lysack, 2011: 7) and as a result it has proved difficult to define and implement in development initiatives (Mhagama, 2015). It is for this reason that the term assumed various definitions by various scholars. Carpentier (2011) for instance, classified ordinary people's involvement in the media into two interrelated forms, participation in the media and participation through the media. The difference between the two is that "participation in the media deals with participation in the production of media output (programme/content-related participation) and in media organizational decision-making (structural/ managerial participation)" (Carpentier, 2011: 68). On the other hand, "participation through the media deals with the opportunities for mediated participation in public debate and for selfrepresentation in the variety of public spaces that characterize the social...."(Carpentier, 2011: 67).

Carpentier (2011) further distinguishes between minimalist and maximalist forms of participation. According to him, in the minimalist form of participation, "media professionals retain strong control over process and outcome, restricting participation to access and interaction, to the degree that one wonders whether the concept of participation is still appropriate" (Carpentier, 2011: 69). This notion of participation by Carpentier is similar in 
character to Arnstein's 'manipulation' and 'therapy' stages of the ladder of participation. While beneficiaries of development interventions at this stage are seen taking part in discussions on interventions that impacts on them, the interventionists are actually not considering their opinion to the intervention. Participants are only made to feel they matter in the scheme of things that affect them but in reality, their concerns do not impact on the development intervention (Arnstein, 1969: 218). In Carpentier 'maximalist' form of participation however, "the consensusoriented models of democracy (and participation) emphasize the importance of dialogue and deliberation and focus on collective decision-making based on rational arguments in a public sphere" (Carpentier, 2011: 67-8). This is linked to Arnstein description of 'citizen power' where partnership, delegated power and citizen control are key stages in participatory decision-making processes. At these stages, decision-making power is redistributed through dialogue and participants tend to retain essential influence over development processes (Arnstein, 1969: 221223).

While acknowledging participation as a central force to CR programming, Community Radio Stations (CRS) will only achieve its developmental objectives if the programmes are well researched, produced and presented in the languages and in a manner that is comprehensible, with the listeners taking centre stage in the whole process of programming and broadcast (Jallov, 2012). In doing so, it can be claimed that the radio promotes knowledge sharing hence helping people to make informed choices on critical issues. For Jallov (2012), listeners become proud and grasp the message easily when local language is used. The programme-content of Community Radio Broadcast (CRB) addresses the people's felt needs and encompasses all key areas such as election issues, women affairs, conflict resolution, human rights and repulsive traditional beliefs. The programming team cut across all sectors of the local economy including farmers, local craftsmen, traditional and religious leaders, women groups, and youth leaders among host of others. All these are in control of content programming and broadcast. Alumuku (2006) notes that it is the provision of entertainment, education, the need to facilitate change, progress and improved living conditions that make CR a special medium for social transformation.

Participatory development demands that every effort be made to have everybody on board. Alumuku (2006; 98), in reference to Hochkheimer (1999), says that it is essential for the CR to identify willing participants in the society and sit down with them to determine how they can work, that is, "who speaks for whom". Since programmes are based on a problem that is determined by situational analysis, in situational analysis the beneficiaries are key players that are charged with the responsibility of identifying the development challenge and suggest remedies. In the production of programmes, conscientisation plays a significant role. Egargo (2008: 15-16), in reference to Heaney (1995), defines conscientisation as an "ongoing process by which a learner moves towards critical consciousness". This exercise makes the people to become aware of their own cultural identity.

There is a strong belief that CR, if well managed, can fill the void left by the national media (both public and commercial). In his research into policy perspectives on CRB in Zambia, Banda (2003: 125) described CR as "a communicative tool that can be used to mobilize communities in support of development initiatives, either those started by the government, the international aid agencies, or the local Non-Governmental Organizations (NGO's)". Banda's view of CR presents it as a part of communication for development processes. Furthermore, "CRS have the potential to promote good governance, transparency and accountability and to have the capacity to mobilize the people to take ownership of the developmental destiny" (Lingela, 2008:126).

According to Egargo, CR operators declared in 1994 during AMARC conference in Slovenia "CR is the best tool to promote freedom of expression, freedom of information, freedom of formation of opinions and active participation of people in development activities". This declaration spelt out clearly the objectives which an ideal CR ought to achieve with particular emphasis on enabling the minority, disadvantaged, the marginalised and socially 
excluded to get information and to participate actively in generating information (Egargo, 2008; 35-36).

CR by far exists to fill the void left by the one way, non-participatory communication media and to demystify mass media, making them more accessible to their audience. Egargo (2008), citing Moemeka (1981), observes that the departure of the dominant paradigm paved the way for a change in development strategy. The emphasis of the new strategy became rural broadcasting, which meant decentralisation of mass media and delegation of the responsibility of programme-production to the rural community members. In reference to Wilbur Schramm, Egargo (2008:40) adds that the local media were seen as better positioned to serve the indigenous people better.

CR is supposed to provide a 'voice for the voiceless', to make possible diversity of opinions and to stimulate people to begin to think critically in order to identify and provide solutions to their problems (Egargo, 2008 \& Jallov, 2012). In order to perform these responsibilities successfully, the radio staff must understand the principles of CR; they have to be trained in community leadership and how to moderate discussions to extract valuable ideas from all participants (White \& Chiliswa, 2012). Further, the staff ought to be trained on how to establish community-based organisations. There is the need to build in staff adequate skills needed to enhance participatory dialogue and debate on critical issues of concern to the larger community.

Rennie (2006) tend to suggest that a CR's impact on development is most felt when it is part of a development project. In as much as this thinking may be true, CR has the potential to promote development in the absence of a project given that communication and the transfer of information play a significant role in development processes (Servaes et al., 2012; Lennie and Tacchi, 2013).

For Ghana, the earliest mention of the concept of CR was in 1995 when Radio Ada, Radio Progress and Radio Peace submitted applications for broadcast frequencies to the then Ghana Frequency Registration and Control Board (GFRCB). Following these applications, Radio Progress was the first of the three pioneer CRS in Ghana to commence broadcast on the $17^{\text {th }}$ of February 1997 in Northern Ghana broadcasting in Dagaare. Subsequently, Radio Ada and Radio Peace commenced broadcast on $1^{\text {st }}$ February 1998 and $1^{\text {st }}$ September 1999 respectively. Radio Ada broadcast in Dangme while Radio Peace broadcast in Fanti. Following a seminar in September 1999 where the International Community Media Specialist schooled the three pioneers "On-Air" CRS in Ghana, the Ghana Community Radio Network (GCRN); an umbrella body of CRS in Ghana was successfully launched on $4^{\text {th }}$ December 1999.

Based on the context it is used, particular CRS may emphasize the significance of certain characteristics, which others may not see as significant. CRS may prioritise the practical service they provide by enabling audience to access and transmit information among them without travelling from one place to another. A station whose broadcasts priority is an ethnic minority in a Cosmopolitan may choose to emphasize on its cultural role yet in other circumstances, a station could define itself primarily by its role of ensuring that vulnerable, marginalized and socially excluded members of the community are able to express their concerns, or promote transparency and expose corruption (Fraser \& Estrada, 2001:20; and Girard, 2007:1).

The CRS is centered within its defined community and remains accountable to it. The station can serve particular communities of interest such as women, youth or linguistic and cultural minorities and its community could be geographic in nature (Girard, 2007:1). Often, the community own and exercise control over the station. In some instances, the legal owner is the community itself, often placed in the custody of a group that has supervisory role over the Station. In other instances, the original owner is an organisation without any profit motive, an cooperative of like minded individuals, a non-governmental agency or a government agency who administers the station in trust of the host community (Girard, 2007:1; and Fraser \& Estrada, 2001:4).

In spite of the legal status of a CRS, its goals and organisational desires are carried out with functional inputs from interested parties within the host community. Members of the host 
community have a responsibility of ownership and are in the capacity to direct the focus of the stations to suit their wishes and community needs. The overall objective of a CRS is to champion the larger interest of their community of interest through their efficient and routine engagements in the station's management and program production processes. The programmes of a CRS are geared towards promoting community development and social empowerment of its audience (Fraser \& Estrada, 2001:4; Girard, 2007:1; and Teer- Tomaselli \& De Villiers, 1998:165). CRS primarily exist to provide support and propel community's development. They do this by adopting strategies that enlist members of the listening community at all levels of the stations' operations. Participation empowers the community members, acknowledges their contribution to the development process through radio and ensures that program content meets community needs (Wigston, 2001:430). Participation in programming can be assured with participatory production formats that motivate and support programme production by interested parties from within the community. This can further be encouraged by organising community fora, and supporting community members to democratically express their opinion on matters brought up for discussions on radio/ at radio fora (Fraser \& Estrada, 2001:20; and Teer Tomaselli \& De Villiers, 1998:165).

Therefore, this paper sets out to examine the levels at, and forms by which community members participate in radio Gaakii's broadcast. Again, the paper investigates the frequency of community members' participation in the stations broadcast and to ascertains the levels of satisfaction (or otherwise) of their participation in the radio broadcast.

\section{Defining the "Community" in Community Radio Broadcast}

According to Mtimde et al. (1998: 12), “the term, 'community' can either be defined as: a geographically based group of persons and/or a social group or sector of the public who have common or specific interests". In Ghana, the National Communications Authority's (NCA) guidelines for the operation of CR (2007), defines a community as having the following characteristics:

"A community must be identified with specific geographical area; the community must have something of central importance to their culture and possess a sense of continuity and traditional values and the community must have some concrete social structure to interact and identify with each other on all aspects of social, cultural and economic needs".

Members of the community usually own CR. This implies that the community members, who are usually motivated by community consciousness and willingness to pool resources, agree that they want their own radio station in order to advance their community interests. In this case "the facilities of a CR are almost invariably owned by the community through a trust, foundation, cooperative or some similar vehicle" (Fraser and Estrada, 2001: 17).

For Ghana's National Communications Authority (2007), "the basic objective of the CRS shall be to serve the cause of the community in the service area of the authorization by involving members of the community in the broadcast of their programmes". For this research purpose, community would mean people living in the coverage zone of the broadcasting service of the applicant organization.

\section{Participatory Development Communication (PDC) Theory}

Mowlana reveals that the African school of development communication emerged out of the continent's post-colonial and communist movements in the late 1960s and early 1970s. He observed that while development communication in Anglophone Africa involved the use of radio and theatre for community education, adult literacy, health and agricultural education, radio was being developed as a means of promoting rural development in Francophone Africa, with sponsorship from the Bretton Woods institutions (Mowlana, 1985). Whilst the continuous research, publications and advocacies of development and literary scholars such as Christopher Kamlongera, Jean-Pierre Ilboudo, Penina Muhando Mlama, Mapopa Mtonga, Derek Mulenga, 
Zakes Mda, Guy Bessette, Celeste Cadiz, Felix Librero, Antonio Moran, Alexander Flor, Pedro Bueno, Rex Navaro, among others shaped the discourse on PDC in development circles (See for example: Quebral, 2012; Bessette \& Rajasundrum, 1996; Bessette, 2004; Cadiz, 2005; Librero, 2004), it is significant to acknowledge the pioneering scholarly works of Prof. Nora Cruz Quebral that marked the beginning of the concept of development communication in the Philippines in 1971 during a symposium in honour of Dr. Dioscoro L. Umani of the University of the Philippines College of Agriculture (Mowlana, 1985; Quebral, 2011).

At the International Conference on Popular Participation in the Recovery and Development Process in Africa in 1990 at Arusha in the United Republic of Tanzania, the mainstreaming advocacy of participation in development initiatives was given a major boost following the adoption of the African Charter for Popular Participation in Development and Transformation (ACPPDT). The charter among other things affirmed the critical need to recognize the role of people's participation in Africa's economic and social recovery processes and development efforts.

The lack of grassroots participation in development communication is blamed for the failure of most development projects. It was therefore imperative for participatory theorists to redefine development communication. One such definition is that communication is "the systematic utilization of communication channels and techniques to increase people's participation in development and to inform, motivate, and train rural populations mainly at the grassroots" (Waisbord, 2000: 17), hence participatory development. PDC paradigm has been defined as "need-oriented, endogenous, self-reliant, ecologically sound and based on participatory democracy and structural transformations" (Servaes, 1996: 32). The key words in this definition by Servaes are 'participatory democracy' and 'endogenous'. PDC theory focuses on community access and participation in development projects.

The paradigm sees access as "the use of media for public service" (Servaes, 1996: 79), and participation as a process of empowering the people to participate in identifying the problem and designing a development programme (Melkote, 1991: 237). In this regard, individuals are active participants in development programmes, projects and processes; they contribute ideas, take initiatives, articulate their needs and problems and assert their autonomy (Ascroft and Masilela, 1989 in Melkote 1991: 237-239). Thus participation requires a higher level of people's involvement in the communication systems especially the media. People have to be involved in the production process, management, and planning of the communication systems. "In this case, the public exercises the power of decision-making within communication enterprises and is also fully involved in the formulation of communication policies and plans" (Servaes, 1996: 79).

The PDC theory pontificates people's involvement in decision-making about issues impacting their lives - a process capable of addressing specific needs and priorities relevant to people and at the same time assisting in their empowerment. Promoting the sustainable and systematic use of communication in the development process helps to ensure people's participation at all levels.

The concept of participatory development according to Okunna (1995: 618) dates back to the 1930s. For him, PDC works on the premise that participation is central to any effective use of communication in the development process, since "it is through participation that sustainable social changes can be achieved". Participatory development itself is the involvement of beneficiary communities in taking decisions that affect their lives. Participation requires that beneficiaries express their views and take suggestions and requests that can be integrated into development policies, programmes and projects (Okunna, 1995).

Paolo Freire is perhaps the most renowned scholar whose critical pedagogy espoused in his book "the pedagogy of the oppressed" became relevant to the concept of PDC. Thomas (1993) thinks Freire's notion of education and his leaning toward participation are based on the conception that the historical vocation of human beings is to be free from the shackles of material and psychological oppression. Freire indeed advocated for beneficiaries of development projects to be involved in the entire process of planning and executing such projects. This call is reflected in Freire's (1970) argument that all individuals have the capacity for reflecting, abstract 
thinking, conceptualizing, taking decisions, choosing alternatives and planning social change. Thomas (1993: 51) quotes Freire as explaining that "authentic participation leads to a freeing, emancipatory experience resulting in actual liberation". Freire disapproved of the kind of educational system, which is based on the premise that knowledge is a finished product, rather than something to be discovered in a dialogue encounter (Ansu-Kyeremeh, 1997, Thomas, 1993). Friere contends that when knowledge is modeled on exogenous fashion and imposed on poor communities, it does not benefit the recipients (Ansu-Kyeremeh, 1997).

Soola (1995: 28) asserts that the micro and communal nature of community participation in the development process require a shift from the big to small and participatory community media. Soola continue to point out that communication at this level moves from uni-directional or unilineal flow of information to a more dynamic, progressively transitional and experience sharing process where one cannot distinguish between "superior or active, super-thinker sender" and "subordinate passive-ignorant receiver" of information (Soola, 1995: 29).

For Okunna (1995), the participatory nature of interpersonal and group media gives rural people an active and important role in their own development. One such medium over the years that encourages peoples' participation and provides the platform for engagement in development planning processes among rural folks is CRB service.

\section{Research Methodology}

This research adopted the cross-sectional survey design in its approach. Multistage sampling technique was used in the sampling process. Specifically, simple random sampling technique was used to sample one district (thus- Saboba District) from a sampling frame of 7 Districts playing host to 8 "on-air" CRS in the Northern region of Ghana as at the time of this study. The method was repeated in selecting 5 listening communities from which the 150 respondents were selected out of a sampling frame of 20 clustered-communities in the Saboba District.

Purposive sampling was then applied in sampling Radio Gaakii out of the two CRS in Saboba because it has a regular broadcast schedule and also because its coverage extends to almost all the districts of the Northeastern corridor of Ghana where more than half of the regions' population resides. Again, this technique was used in recruiting the Programs Director and Station Coordinator of Radio Gaakii as key informants for this study.

Accidental sampling technique was deployed in the selection of 150 individual respondents from the sampled listening communities for the survey. Semi-structured questionnaires and interview schedules were the two main tools used in collecting primary data for the purposes of analysis.

\section{Findings and Discussions}

\section{Socio-demographic Data}

- Age and Sex Distribution of Respondents

Table 1: Cross-tabulation of respondents' age range and sex distribution

\begin{tabular}{cccc}
\hline \multirow{2}{*}{$\begin{array}{c}\text { Age Range of } \\
\text { Respondent }\end{array}$} & \multicolumn{2}{c}{ Sex of Respondent } & Total \\
\cline { 2 - 3 } & Female & Male & \\
\hline $18-24$ & 15 & 8 & 23 \\
$25-29$ & 8 & 16 & 24 \\
$30-34$ & 5 & 13 & 18 \\
$35-39$ & 6 & 6 & 12 \\
$40-44$ & 8 & 5 & 13 \\
$45-49$ & 9 & 9 & 18 \\
$50-54$ & 7 & 6 & 13 \\
$55+$ & 17 & 12 & 29 \\
\hline
\end{tabular}




Total $\quad 75 \quad 75 \quad 150$

Source: Field Data

The table above presents the age and sex distribution of respondents. Of the 75 female respondents, the minority age range was found to between 30-34 years who constitute 7 percent while the majority age range was respondents aged $55+$ constitute 23 percent. For the 75 male respondents, the minority age range between 40-44 years constituted 7 percent whilst the majority age range was found to be respondent's age 25-29 years constituting 21 percent. Overall, the minority age-range respondents was 35-39 years who constitute 8 percent while the majority age range respondents was $55^{+}$constituting 19 percent of the 150 sampled respondents.

- Educational Status of Respondents

Table 2: $\quad$ Educational background of respondents'

\begin{tabular}{lcc}
\hline Highest Level of Education & Frequency & Percentage \\
\hline No Formal Education & 61 & 41 \\
Primary & 14 & 9 \\
Junior High School & 12 & 8 \\
Senior High School & 26 & 17 \\
Post-Secondary & 15 & 10 \\
Tertiary & 22 & 15 \\
\hline Total & 150 & 100.0 \\
\hline
\end{tabular}

Source: Field Data

The table above presents data from an investigation into the educational backgrounds of respondents. The data revealed that, 41 percent of the 150 respondents in this study had no formal education while 8 percent schooled up to the Junior High School level. Also, 9 percent of respondents disclosed they schooled up to primary level with 17 percent completing Senior High School. The results further indicate 10 percent and 15 percent of the 150 respondents schooling up to Post-Secondary and Tertiary levels respectively.

This statistic supports the 2010 Population and Housing Census (PHC) in Ghana, which reveals that about 64 percent of the people in Saboba had no formal education. This is also not very different from the overall educational background of the people of the Northern region as per the 2010 census. The low literacy rate is also akin or associated to rural communities of the country. In planning rural development projects therefore, it is critical to consider the educational backgrounds of beneficiary communities. This does not only facilitate acceptance and utilization of such facilities and projects but also enhances support and promote sustainability of such projects and programmes. In carrying out programmes in rural communities therefore, it is important to use channels that can reach the uneducated and mostly marginalized and socially excluded.

- Ethnic Background of Respondents

Figure 1: Bar Graph showing the ethnic background of respondents 


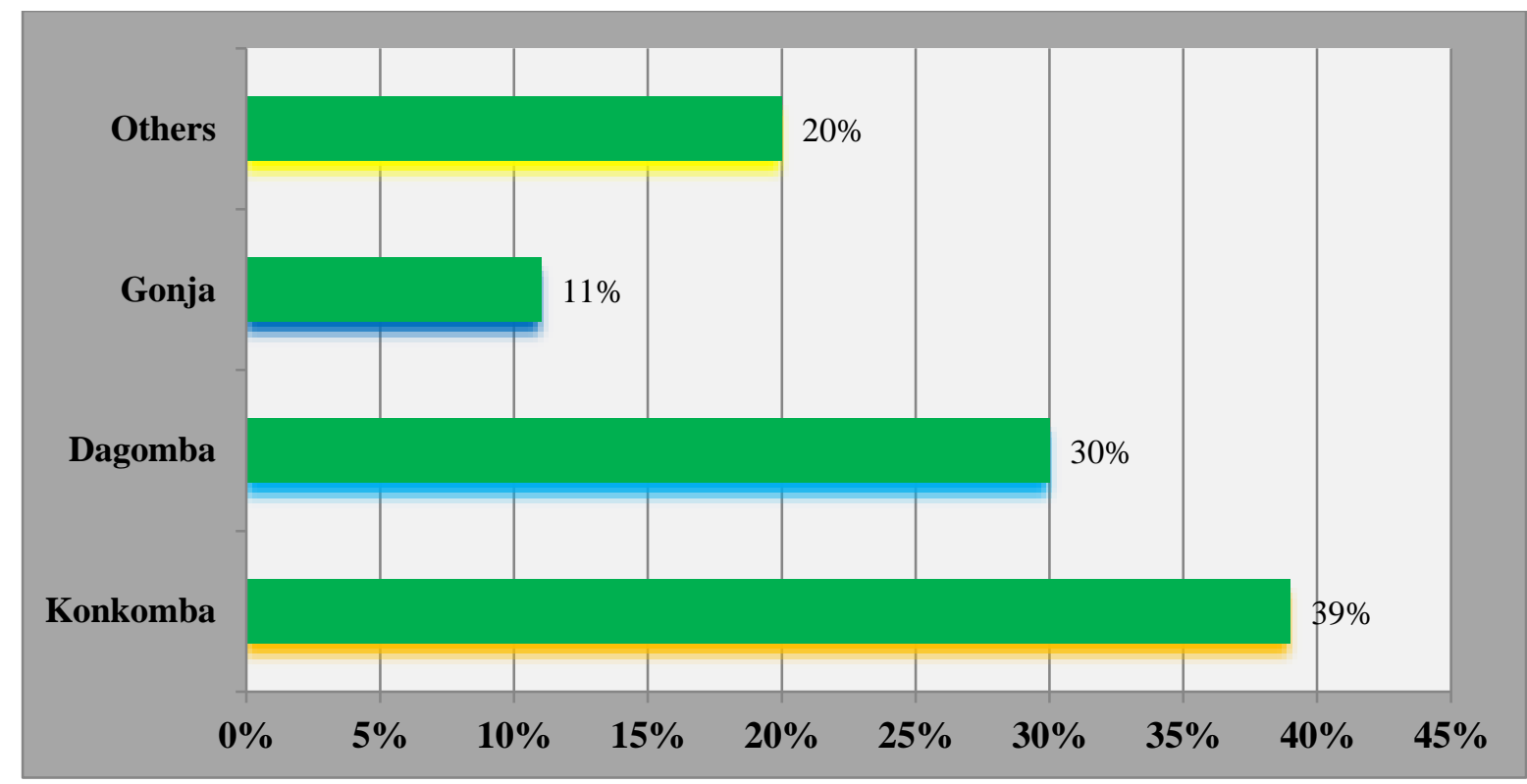

\section{Source: Field Data}

Language is considered a key component of CRB. Broadcast contents of CRS are mostly modeled around the languages spoken by the community in order to foster greater understanding and active community participation. Language in CRB is also a way of promoting the cultural identity of the community it serve and as well give a sense of belonging to members of the listening community. Although the study community is a predominant Konkomba community, sample respondents were representative of ethnic groups that reside in the district. From the figure above, Konkombas constitute 39 percent of sampled respondents while Dagombas make-up 30 percent of respondents. All other minority ethnic groups (Mossi, Mamprusi, Chokosi, Hausa, Ewe, Fulani and Yoruba) that reside in the district constitute 20 percent of respondents with Gonjas forming 11 percent of the 150 respondents in this study. This distribution is also reflective of the ethnic groups that live in Ghana's Northeastern corridor.

\section{Levels and Forms of Community Participation in Community Radio Broadcast}

There appears to be a symbiotic relationship between Carpentiers' classifications of people's engagement with the media and Sherry Arnstein's proposition of citizen participation. Using a ladder to illustrate the nature of power structure and how they interact in society, Arnstein's (1969) argues that citizen participation follows a continuum with non-participation at the bottom of the ladder and citizen power at the very top of the ladder. In between the two ends however, is token participation. Each stage on the ladder is further categorised into various levels of participation. For example, the non-participation stage is characterized by manipulation and therapy. Arnstein argue that there is no participation at this stage and the levels ascribe are aimed at enabling "power holders to 'educate' or 'cure' the participants" (Arnstein, 1969: 127). Also, at the stage she described as Tokenism that involves informing, consultation and placation, she asserts that people's views are sought at that stage but they are not involved in making final decisions. At the 'Citizen power' stage that features partnership, delegated power and citizen control, it is regarded the highest level of participation where the community is accorded the rights of stakeholders by assuming full ownership and control over decision-making processes in development initiatives (Arnstein, 1969).

Based on the symbiotic relationship between Carpentier (2011) and Arnstein's (1969) theses therefore, this paper proposes to evaluate the levels of community participation in community radio using four indicators as follows:

i. Programme Design Stage - At this stage, respondent should be involve in deciding the kind of programmes that should be broadcast. It is also at this stage that the 
planning of the entire broadcasting structure revolves. The kinds of programmes to air and at what time, in which language and the mechanism to use.

ii. Programme Production Stage - In this stage, respondent should be involved in the actual production of the broadcast messages. It involves even programme recording on the field or in the studio.

iii. Programme Listening Stage - For this stage, respondent should be actively involved in not only listening to broadcast messages but participate through calls or as part of a radio listener group that discusses topics raised during broadcast.

iv. Programme Financing Stage - This stage involves sponsoring of broadcast programmes, placing advertisement and or announcements, paying subscription fees (if applicable), voluntary donations and any other contribution in kind (material resource) or cash (money) towards the running of a particular programme or the station in general.

Figure 2: $\quad$ Bar Graph showing the levels of respondents' participation in Radio Gaakii Broadcast

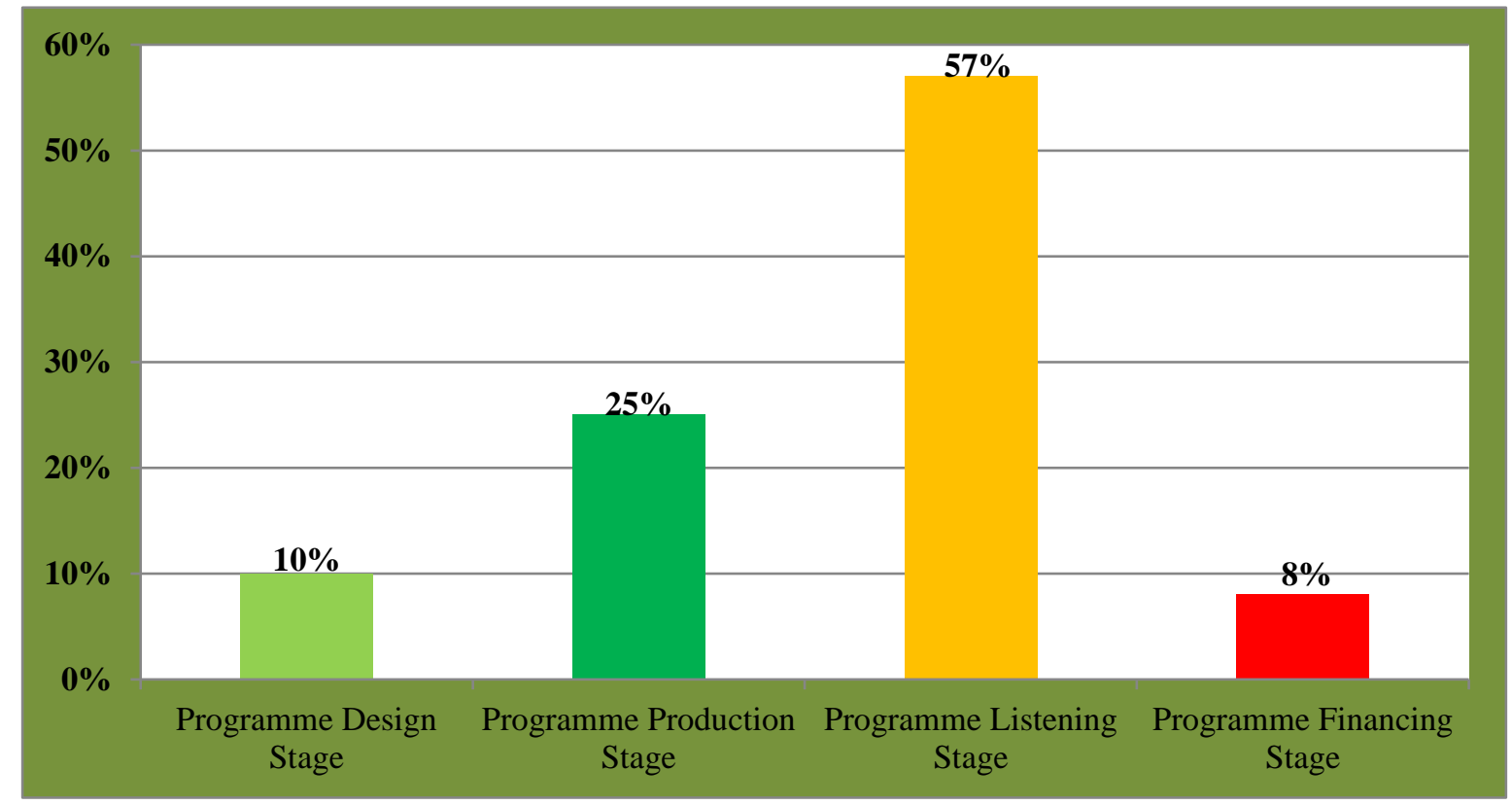

Source: Field Data

It is refreshing to note that, the study discovered a generally higher participation in CRB as 84 percent of sampled respondents in this study disclosed their participation in CRB whereas, 16 percent of respondents do not participate in their CRB.

From figure 2 above however, the data reveals a higher participation of community members at the broadcast listening stage. As high as 57 percent of respondents who participate in CRB do so only at the programme listening stage in the broadcast cycle. Whereas only 8 percent of respondents are involved at the programme financing stage of CRB cycle, 25 percent of respondents participate at the broadcast production stage. 10 percent of respondents are however involved at the programme design stage of the CRB cycle.

The Programs Director of the radio station disclosed in an interview that in deciding on the kind/ type of programmes and to some extent the content of such broadcast, the station first carry-out an audience research to ascertain the needs and concerns of the listening community.

"Sometimes, our programmes are informed by the community we serve through an audience-based research. We do ask the people what their expectations are in relation to our radio programmes. Their responses are then used to plan and design the programmes". 
He however conceded that this was not done often and was also limited to the district capital to the neglect of other listening communities.

"... I must however add that, this is not done routinely. When it is done, the research is often based in the township and does not include the surrounding communities because we do not have the logistics such as means of transport and even recorders to engage so many communities in our research. But all the same, our people can be said to be homogenous in character. The challenges in one community can be found in other surrounding communities".

The Station Coordinator also disclosed that the station is able to engage a few communities during programme production especially when such programmes are under sponsorship or produced for an interest group such as a non-governmental organisation.

\section{"For some of our sponsored programmes that need to be recorded at the field with the community members, we are able to do so. Doing field-based programme production is sometimes costly and needs some good budget-line. But we do not get such sponsorships often. As such, we rely very often on the programme listening stage to estimate the level of community participation in our broadcast since we have call-in sessions in many of our daily broadcast".}

Although the radio station is registered as a community-based radio project licensed under Theovision Radio Network- a church organisation whose mission is to build up communities through effective and desirable programs that empowers its audience to be well informed, the community is not involved in the management of the station in a democratic manner but rather, the church leadership extends an invitation to any person they deem fit to serve on the Community Radio Council. This apparently is the case with CRS established for the community by either Non-governmental organisations or church associations (see for example Myers, 2000 and Moemeka, 1981). However, the need for a means of communication in the community should emanate from among the community members themselves. All sources agree that a CRS is one that is owned by the people it serves (Steins, 2002: Fairchild, 2001 and Frazer \& Estrada: 2001). This principle implies in foundational terms that the community whose members, motivated by community consciousness and willingness to pool resources, agree that they want their own radio station in order to advance their community should initiate their radio project.

For any community radio project to be effective there should be open access and participation by the community members in the stations' affairs. Access and participation are viewed as allied principles in community-based projects, and these are also crucial pillars of community radio. Access in this regard implies the availability of broadcasting services to all the community members whilst participation implies that the community is actively involved in planning and management, and also provides producers and performers (Fraser, Estrada: 2001, 16).

In an in-depth interview with the Station Coordinator of radio Gaakii, he disclosed that the station has a council with representation from various stakeholders such as traditional leaders, other religious organisations, the youth groups, women groups, traders, farmer-groups and even the district assembly. Regrettably however is the fact that the leadership of the church identifies these representatives and invited to serve on the board.

"We have a Community Radio Council with representation from the various stakeholders in our catchment areas. However, it's the church serving as custodian to the radio station that identifies and invites people whom they deem as fit to serve on the council. Even though all those serving on the council are members of our listening communities, they are often not elected or nominated by the groups they supposed to represent. The church also appoints the chairman of the council. As a result of this, there is a huge financial burden on the station as members who serve on the board 
often expect monetary rewards for their services rather than offering it in community service".

There is limited interest and/ lack of active community participation in financing and maintaining the radio station. One major factor that often gives raise to this situation in community projects is the apparent lack of a sense of community ownership and control in such projects. Once the community member's interest does not reflect in the project initiation or design, they often view such projects as an imposition or at best, describe it as alien to them and will often trace its source to either an individual or an association. In such instances, the motivation to contribute to its sustainability will be lost.

In the words of the Director of programs at Gaakii, the community's lack of interest in funding the stations' programmes is summarised below:

"As for participation in financing, it is a big issue for us. We have tried severally to court community interest in ensuring the sustainability of the station through voluntary funding, contributions and donation but it is not forthcoming. We rely on very limited sponsorships and charges from announcements and advertisements from the community to run the station".

His view was corroborated by the Station Coordinator during a separate interview.

"Indeed, it is the initial orientation of the people about this radio station that is now causing these financial challenges to us. Perhaps, we should have involved the community in deciding even where to set-up the station and some other pertinent issues such as defined ownership status, community interest and perbaps, staff recruitment that we did not handle well at the beginning".

Figure 3: Bar Graph showing respondents' form of participation in CRB

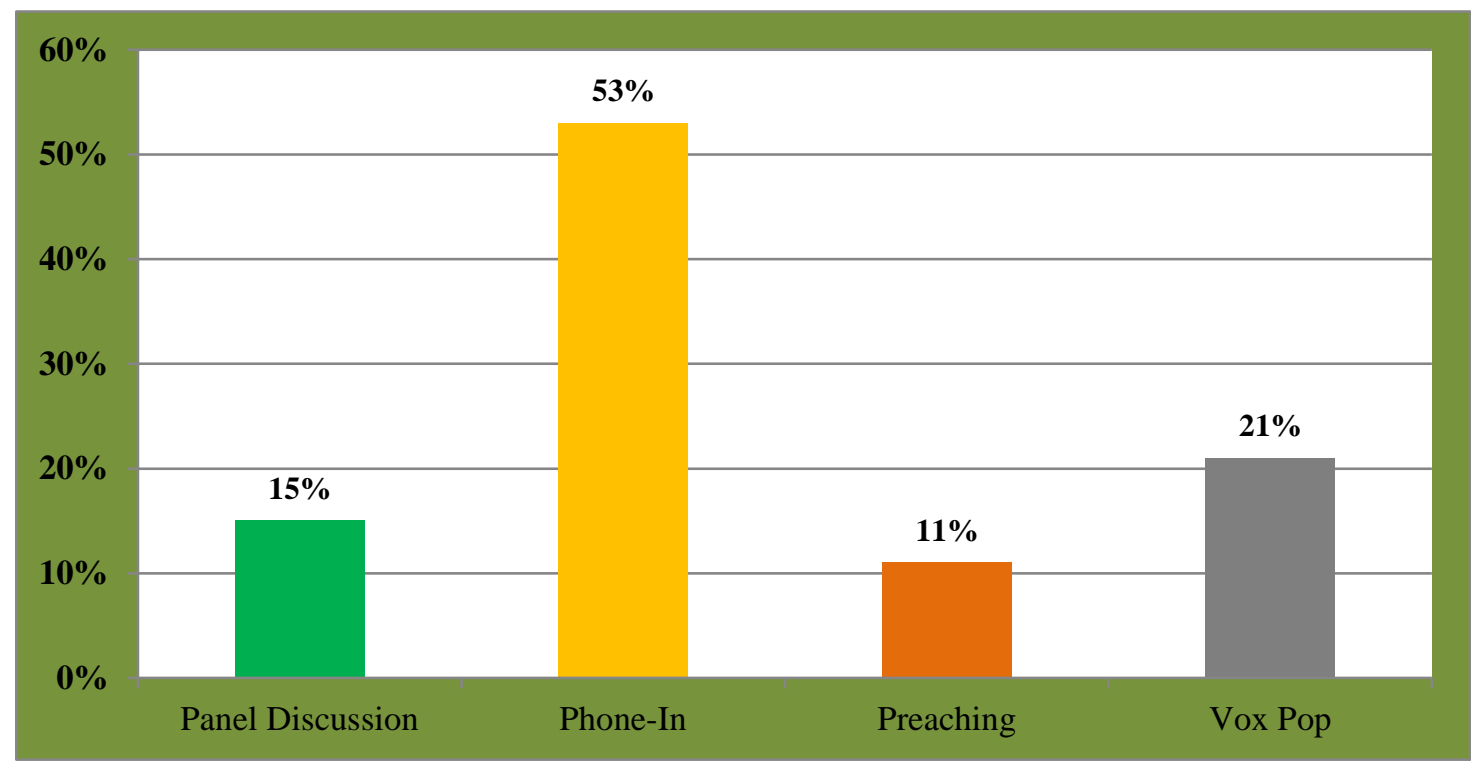

Source: Field Data (2015/2016)

In terms of the respondents' form of participation in CRB, the study discovered that majority of community members participate through the use of mobile phone during phone-in sessions of broadcast. As much as 53 percent of respondents participate through phone-in during programme listening especially when the programme involves call-in-segments while 15 percent of community members participate in the form of panel members during various broadcast sessions that require discussants. The study also discovered that 21 percent of respondents participate through vox pop with the remaining 11 percent usually engaged as preachers (Christians and Muslims). 
During an in-depth interview with the Programs Directors of Radio Gaakii, it was revealed that about 60 percent of the stations programmes have call-in sessions that allow listeners to phone-in and participate:

"One of the easiest ways community members participate in our broadcast is through phone-in especially during broadcast. I can say that with about 60 percent of our daily programmes having call-in sessions especially our educational programmes for farmers and the entertainment segments, majority of our listeners are offered the best opportunity to participate. And from my experience here so far, phone-in participation has been encouraging though it might not be as effective as directly engaging them on the field and recording their concerns to be re-broadcast".

In a similar interview with the Station Coordinator, it was revealed that resource constraints hamper the expansion of community participation beyond the use of mobile phones. $\mathrm{He}$ expressed great worry about the fact that the poor farmer who cannot use a mobile phone or does not have enough mobile credit to place a call during broadcast is literally denied his right to participate in discussion and to make his voice heard.

"Certainly a lot of people are denied the opportunity to participate in our broadcast not because there are rules barring them from participating but obviously because of the buge barrier created as a result of the lack of resources to operate. If we had resources, our team could create more opportunities to allow for wider and active participation of the community in our broadcast".

Acknowledging the critical role of community participation in CRB and the need for Radio Gaakii to provide a strong voice for the voiceless, marginalized and socially excluded, the Station Coordinator remarked:

"We do it for such programmes that have NGO support-an example is one of our farmers' programme we call SEND-Ghana Fostering Hour. The first 30 minutes of that programme is a live transmission of farmers in a selected community discussing ways of improving their liveliboods strategies while the remaining 30 minutes is devoted to in-studio expert-discussions intertwine with call-ins. It has proved so far to be an effective way of getting the communities to participate in our broadcast".

\section{Frequency of Community Participation in Community Radio Broadcast}

Available data from this research indicate that the frequency of community participation in CRB is regular only to the extent that daily programme broadcast have call-in sessions. Since the majority of community members participate at the programme listening stage and through call-in sessions, it follows from then that as much as the radio broadcast comes with the opportunity for the listener to call-in and share his/her experience and concerns, participation will always be higher for those who are privileged to own or have access to a mobile phone.

Table 3: Frequency of respondents' participation in CRB

\begin{tabular}{lcc}
\hline \multicolumn{1}{c}{ Frequency of Respondents' } & \multicolumn{2}{c}{ Counts } \\
\cline { 2 - 3 } Participation & Frequency & Percentage \\
\hline Very Often & 23 & 20 \\
Quite Often & 43 & 38 \\
Often & 25 & 22 \\
Not-Quite-Often & 14 & 12 \\
Not-Very-Often & 9 & 8 \\
\hline \multicolumn{1}{c}{ Total } & 114 & 100 \\
\hline
\end{tabular}

Source: Field Data 
Using a likert-scale, the study measured the frequency of participation in CRB. The survey found out that 38 percent of community members 'Quite Often' participate in the stations' broadcast whereas 22 percent 'Often' participate. Again, the study discovered that 20 percent 'Very Often' participate in CRB. The overall effect is that, frequency of community participation in CRB is high at the programme listening stage often through listener call-in segments.

This finding confirms the assertion of the Programs Director that about 60 percent of their station programmes have call-in sessions that allows for participation of the community members during the programme listening stage. The Programs Director also stated that during call-in sessions, the excitement to call is often high especially for farmers and culturally tailored programmes. He asserts:

"... during certain programmes where we open the phone-lines for listeners to call in with their contributions, concerns or questions, we are often able to put about 20 to 25 calls through in most call-in sessions that last for about 30 minutes. Sometimes, the phones keep ringing even after the session ends with some people complaining a couple of times of not being able to get through with their calls".

The Programs Director reveals that the most times they receive the highest calls from listeners are often during education related programmes such as those that borders on farming, health, sanitation, culture and politics. He added that calls coming in during entertainment related programmes such as 'Story-Time (Toeli)' or 'Local Music with Dedications' are often encouraging and spices up the day.

\section{Level of Satisfaction of Community Participation in CRB}

Table 4: Respondents' level of satisfaction in participating in CRB

\begin{tabular}{lcc}
\hline Respondents' Level of Satisfaction in & \multicolumn{2}{c}{ Counts } \\
\cline { 2 - 3 } Participating in Gaakii's Programmes & Frequency & Percentage \\
\hline Very Dissatisfied & 10 & 9 \\
Quite Dissatisfied & 37 & 32 \\
Quite Satisfied & 34 & 30 \\
Satisfied & 15 & 13 \\
Very Satisfied & 18 & 16 \\
\hline \multicolumn{1}{c}{ Total } & 114 & 100 \\
\hline
\end{tabular}

Source: Field Data (2015/2016)

In the case of respondents' level of satisfaction, a five point Likert-scale was developed to obtain responses from listeners. The ensuing results showed mixed responses as slight majority (32 percent) disclosed they are quite dissatisfied with their level and form of participation in community radio with some 9 percent indicating they are very dissatisfied. Also, 30 percent of listeners indicate they are quite satisfied with their participation in community radio while 16 percent feel very satisfied. The remaining 13 percent however disclosed that they are satisfied with their participation in CRB. The net effect is that, community members who do participate in $\mathrm{CRB}$ are generally satisfied at their level and form of participation.

\section{Factors Motivating Community Participation in Community Radio Broadcast}

An investigation into the factors that motivate and encourage listeners to participate in CRB discovered that, half (50 percent) of the sampled respondents participate in radio broadcast because it enhances their knowledge. Some respondents in this category revealed that they get to learn new ideas and adopt new innovations and technologies especially in the areas of agriculture, health and most importantly their culture. The remaining 50 percent of respondents disclosed they are often motivated to participate because they get satisfaction (27 percent of respondents), they are empowered (11 percent of respondents), economic benefits such as increase in sales and 
allowance in the case of panel discussion (9 percent). The other 3 percent however disclosed other factors of motivation such as gaining popularity. Figure 4 below gives an illustration.

Figure 4: Pie Chart showing factors that motive participation in CRB

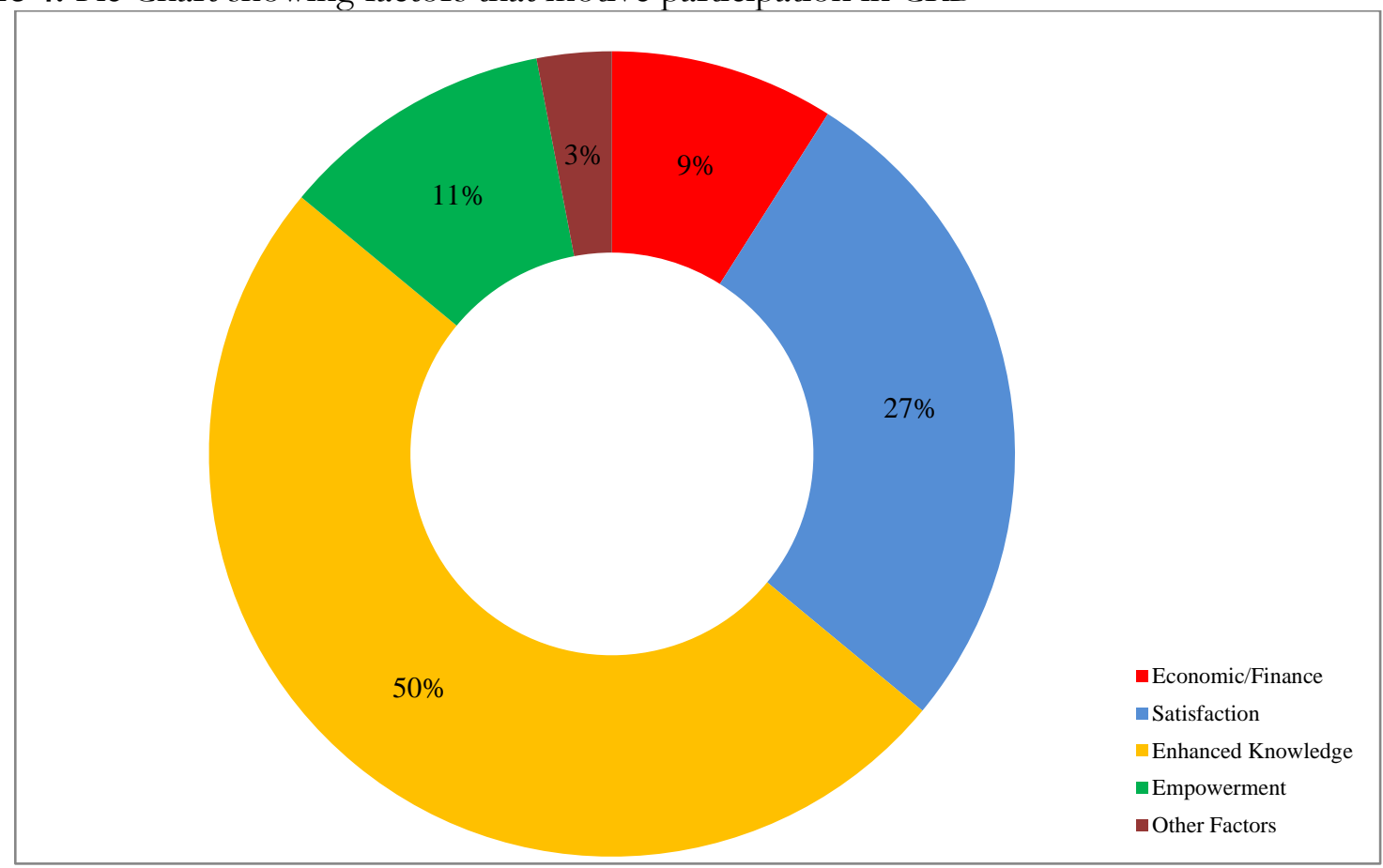

Source: Field Data (2015/2016)

\section{Factors Impeding Community Participation in Community Radio Broadcast}

Figure 5: Bar-Chart showing factors that impedes participation in CRB

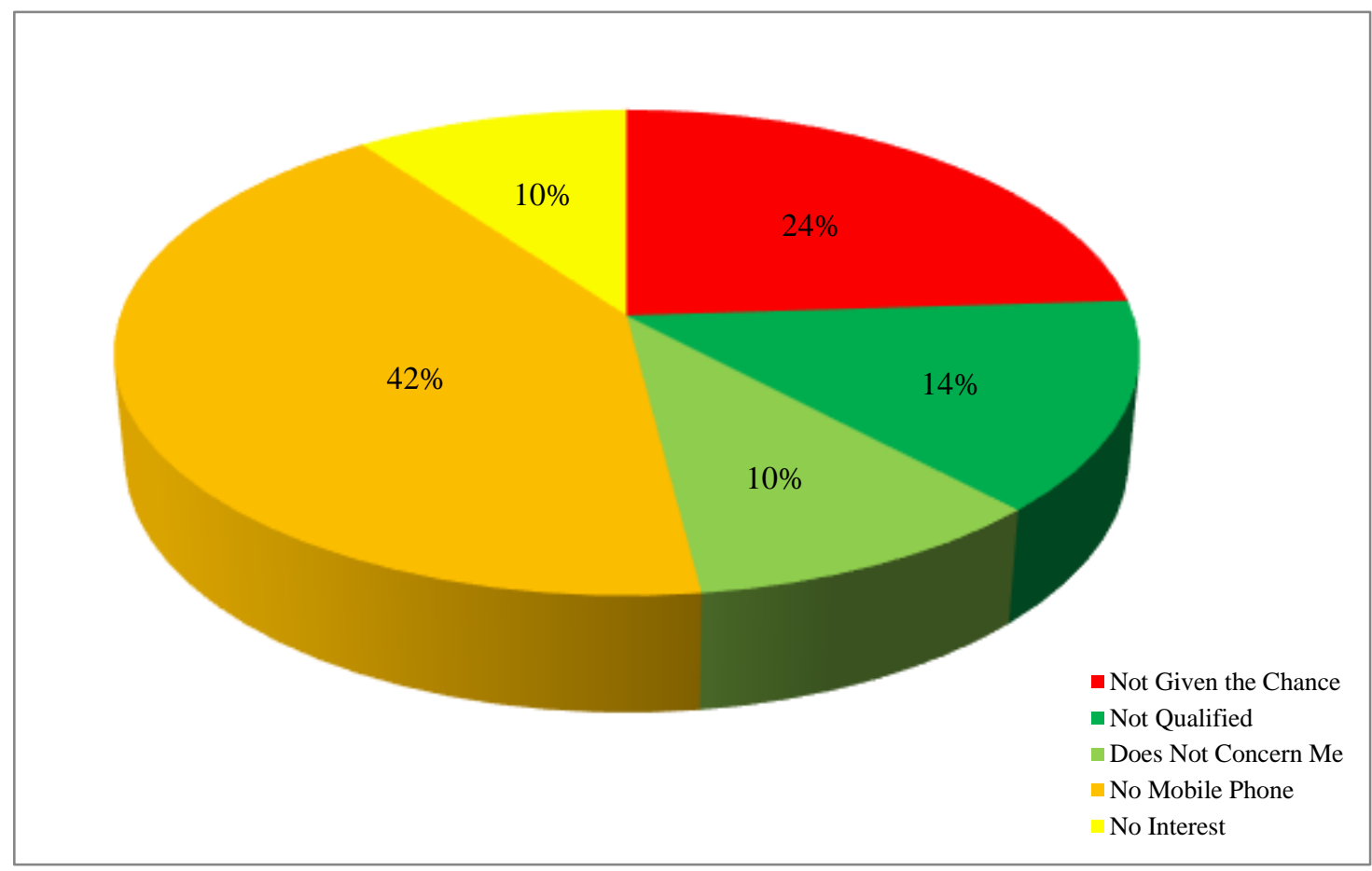

Source: Field Data (2015/2016) 
The study discovered that 42 percent of respondents' who do not participate in CRB attributes their inability to the lack of mobile phones since call-in sessions are the commonest form one can participate in their CRB. Also, 24 percent of community members who do not participate in the CRB blamed it at the doorstep of the CR management for not providing them the chance to participate. Some of the respondents disclosed how they have severally made efforts to get their calls go through during call-in segments but have never being successful. However, 14 percent holds the notion that they are not qualify to participate in CRB assigning reasons such as illiteracy and inability to use mobile phone with 10 percent each disclosing they have no interest and the programmes does not concern them. Figure 5 above presents in graphics, the results of factors that impede respondents' participation in CRB.

\section{Conclusion}

The study has demonstrated that although community participation in the management, governance, programming and financing decisions of Radio Gaakii is limited to the extent that one wonders if the concept of participation is still relevant, the community's participation in CRB in particular is high on the average. The influx of mobile phones in the country has made it much easier for community-based radio listeners to participate in live studio discussions during programme listening. This new mode of participation gives satisfaction to listeners who are often able to follow discussions, contribute ideas, clear their doubts and even send out greetings to family and friends. This practise has enhanced CR listenership status in rural areas of the North and has increased the frequency of participation in community radio broadcasting.

\section{Recommendations}

CRS should involve members of the listening communities in its management, governance, programming and financing decisions through democratic processes. The full involvement of the community in these areas will give the community a sense of ownership and control thereby limiting the powers and influence of donors or sponsors in particularly programming decisions.

As a turning point, the current management of Radio Gaakii (and all other CRS in Ghana) should endeavour to establish Radio Listening Clubs (RLC's) within their broadcast areas or communities. These RLC's should be empowered through skills development and training, to enable them to scope community challenges, table those challenges for discussions and facilitate effective and efficient discussions on radio platforms in ways that will encourage diverse opinions. It is prudent to also train members of the RLC's on programme production and also enhance and sharpen their fund raising skills so that they can produce programmes and help in mobilizing funding for the running of the station. It is particularly imperative to ensure that these RLC's are based on various interest groups such as farmers, youth, women, artisans, the physically challenged and minority ethnic groups that abound in the broadcasting communities. These people should be given equal access and opportunities to studio equipment and other programming platforms, discussions as well as organized activities.

In $\mathrm{CRB}$, the community remains the focal point. As such, their active participation in all spheres of the station is imperative. It is therefore recommended that the powers of decisionmaking be transferred to the community in situations where such radio stations are established through donor funds. To achieve this, members of the listening community should be sensitized, empowered, encouraged and motivated to volunteer their time, knowledge and skills in support of the operation of the CRS. This will not only reduce the stations' operational cost but would eventually improve on the quality of programmes and services rendered to the community since volunteers would normally be interested in offering services in areas they have competence such as programme production, agricultural extension, public health, education, culture and even common laws. Volunteerism in these areas will gradually strengthen and consolidate the relationship between the CRS and the community while reinforcing community ownership and control by virtue of mutual involvement. 


\section{References}

Alumuku, P.T. (2006). Community Radio for Development: The World and Africa. Nairobi: Paulines Publications Africa.

AMARC. (1998). What is community radio? A resource guide. Lusaka: AMARC \& Panos Publishers.

Ansu-Kyeremeh, K. (1997). Communication, education and development: exploring an African cultural setting. Legon, Accra, Ghana Universities Press.

Banda, F. (2003). Community radio broadcasting in Zambia: A policy perspective. Unpublished PhD Thesis submitted at the University of South Africa.

Bessette, G. 2004. Involving the community: a guide to participatory development communication. Ottawa: South Bound printing.

Bordenave, J. D. (1994). 'Participative communication as a part of building the participative society'. In S. A. White (ed.). Participatory communication: Working for change and development. Beverly Hills: Sage, pp. 35-48.

Cadiz, M. 2005. Communication for empowerment: the practice of Participatory communication in development, in Media and global change: rethinking communication for development. Edited by Hemer, O \& Tufte, T. California: Thomson Learning: 145-158.

Carpentier, N. (2011). 'The concept of participation: If they have access and interact, do they really participate?' Communication Management Quarterly, No. 21, pp.13-36.

Egargo, F. N. (2008). Community Radio Broadcasting in the Philippines. Navotas City. National Book Store.

Fairchild, C. (2001). Community radio and public culture. New York, Hampton Press.

Fraser, C. \& Restrepo-Estrada, S. (2002). Community Radio for Change and Development. Thousand Oaks, CA and New Delhi, 1011-6370; Sage.

Freire, P. (1970). Pedagogy of the Oppressed. New York: Seabury Press.

Ghana Statistical Service (2013). 2010 Population and Housing Census-Northern Regional Analytical Report; Accra: Ghana Statistical Service.

Girard, B. (2007). What is Community Media? http://man.comunica.org/archives/101 Accessed 8 May 2015.

Howley, K. (ed.). (2010). Understanding community media. Thousand Oaks: Sage.

Jallov, B. (2012). Radio Empowerment: Voices of Building a community. Krogegaard, Gudhjemvej 62 DK 3760 Gudhjem, Denmark. Empower house.

Kumekpor, T.K.B (2002). Research methods and techniques of social research. Sonlife and Services, Accra, Ghana.

Leeuwis, C. 2000. Reconceptualising participation for sustainable rural development: towards a negotiation approach. Development and change. (31): 931-959. Blackwell Publisher.

Lennie, J. and Tacchi, J. (2013). Evaluating communication for development: A framework for social change. Oxon: Routledge.

Librero, F. 2004. Community broadcasting concept and practice in the Philippines. Eastern Universities Press. Singapore 
Lingela, M. B. (2008). 'Community broadcasting in SADC: An overview', Gender and Media diversity Journal. Gender Links: Southern Africa: Available at: http://www.genderlinks.org.za. Accessed on 08/07/2015.

Melkote, S. R. \& Steeves, H. L. (2001). Communication for development in the Third World: Theory and practice for empowerment. London, SAGE Publications.

Mhagama, P.M. (2015). Community radio as a tool for development: A case study of community radio stations in Malawi. Unpublished thesis submitted for the degree of Doctor of Philosophy at the University of Leicester.

Mtimde, L. 2000. Sustainability for Community Radio. A paper presented at the Namibia Community Broadcasting Conference. http://www.ourmedianet.org/members/Mtimbe/Mtimbe CommRadiSustain.rtf (Accessed: 29t June 2015).

Myers, M. (2000). 'Community radio and development: Issues and examples from Francophone West Africa'. In R. Fardon and G. Furniss (eds). African broadcast cultures. Harare: Boabab.

National Communications Authority. (2007). http://wmw.nca.org.gh/51/116/IndustryInformation.html (Accessed 27 December 2015).

Okunna, C. S. (2000). Mass media gender images and the Nigerian civil child. A paper presented at Summit 2000 in Toronto, Canada.

Rennie, E. (2006). Community media: A global introduction. Oxford: Rowman and Littlefield Publishers, Inc.

Servaes, J. (2002). Communication for Development: One World, Multiple Cultures. New Jarsey, Hamptom Press Inc.

Soola, E. O. (1995). De-massifying the development process: The role of communication in community participation for sustainable development. African Media Review, 9 (2), 11 - 13.

Tamminga, P. (1997). Is community radio an effective tool for grassroots development? A case study of two Honduran NGO's. Ottawa: Simon Frazer University.

Taylor, Celia R. (1994) "The Right of Participation in Development Projects," Penn State International Law Review: Vol. 13: No. 1, Article 3. Available at: http://elibrary.law.psu.edu/psilr/vol13/iss1/3

Thomas, P. (1993). Participatory development communication, philosophical premise. In S. White, K. S. Naik \& J. Asorofi (Eds.). Participatory communication: Working for change and development, Thousand Oaks CA, Sage.

UN General Assembly, Vienna Declaration and Programme of Action, 12 July 1993, A/CON. 157/23, available at: http://www.refworld.org/docid/3ae6b39ec.html (Accessed 5 May 2018]

White, R. \& Chiliswa, Z. (2012). Community radio in Kenya: Problems and Promise. A paper presented at the community communication section International Association of Media and Communication Research. Durban.

Wigston, D. (2001). Radio Production. In Fourie, P. J. (Ed). Media Studies: Content, Audiences and Production. Lansdowne: Juta Education.

World Bank. 1996. The World Bank participation sourcebook (English). Washington, D.C.: The World Bank. http://documents.worldbank.org/curated/en/289471468741587739/The-World-Bankparticipation-sourcebook

Zakus, D. L. \& Lysack, C. L. (1998). 'Revisiting community participation: Review article', Health Policy and Planning, Vol. 13, No. 1, pp. 1-12. 